\title{
A PARENTALIDADE NO CICLO DE VIDA ${ }^{1}$
}

André de Carvalho-Barreto*

RESUMO. Esta investigação realizou uma revisão da literatura nacional relacionada à parentalidade na Psicologia. Foi feita uma busca nas bases SciELO, PePSIC e IndexPsi, obtendo-se 32 artigos. Desses, 46\% eram teóricos, 50\% empíricos e $4 \%$ revisão da literatura. As principais linhas de pesquisa sobre a parentalidade localizadas nas produções foram a Parentalidade na transição de vida $(\mathrm{f}=10)$, a Relação de gênero na parentalidade $(\mathrm{f}=7)$, a Parentalidade em contextos adversos $(\mathrm{f}=7)$, a Parentalidade na adoção $(\mathrm{f}=5)$ e a Parentalidade homoafetiva $(\mathrm{f}=3)$. Dois dos principais resultados foram a polissemia no conceito de parentalidade e a confusão conceitual entre parentalidade e paternidade. Concluiu-se que o estudo da parentalidade é ainda recente no Brasil, por isso são necessárias mais pesquisas para ampliar sua compreensão, as quais devem incluir outras fases do desenvolvimento além da vida adulta, além de aspectos do desenvolvimento normativo.

Palavras-chave: Desenvolvimento do adulto; desenvolvimento psicossocial; psicologia do desenvolvimento.

\section{PARENTING WITHIN THE LIFE CYCLE}

ABSTRACT. This research conducted a review of national literature related to parenting in Psychology. A search of the SciELO, and PePSIC INDEXPSI was made, obtaining 32 items. Among them, 46\% were on theoretical and $50 \%$ on empirical issues and $4 \%$ were on the revision of literature. The most important areas of research on parenting have been the topics Parenting within Life Transition $(f=10)$, Gender Relations within Parenting $(f=7)$, Parenting under Adverse Conditions $(f=7)$, Parenting within Adoption ( $f=5$ ), and Homo-affective Parenting $(f=3)$. One major result was the concept of polysemy in parenting and conceptual confusion between parenting and fatherhood. It has to be concluded that the study of parenting is still recent in Brazil, which requires further research to broaden their understanding and to include other phases of development beyond adult life as well as aspects of normative development.

Key words: Adult development; psychosocial development; developmental psychology.

\section{LA PARENTALIDAD EN EL CICLO DE VIDA}

RESUMEN. Esta investigación realizó una revisión de la literatura nacional relacionada a la parentalidad en la Psicología. Se hizo una búsqueda en las bases SciELO, PePSIC e IndexPsi, en las cuales se obtuvieron 32 artículos. Entre estos, el $46 \%$ eran teóricos, 50\% empíricos y $4 \%$ eran sobre revisión de literatura. Las principales líneas de investigación sobre la parentalidad encontradas fueron la Parentalidad en la transición de vida $(f=10)$, la Relación de género en la Parentalidad $(f=7)$, la Parentalidad en contextos adversos ( $f=7)$, la Parentalidad en la adopción $(f=5)$ y la Parentalidad homoafectiva $(f=3)$. Dos aspectos que llaman la atención fueran la polisemia en el concepto de parentalidad y la confusión conceptual entre parentalidad y paternidad. Se concluyó que el estudio de la parentalidad aún es reciente en Brasil, lo cual demanda más investigaciones para ampliar su comprensión, incluyendo otras fases del desarrollo, además de la vida adulta así como aspectos del desarrollo normativo.

Palabras-clave: Desarrollo del adulto; desarrollo psicosocial; psicología del desarrollo.

1 Este estudo foi desenvolvido no âmbito da disciplina Psicologia do Desenvolvimento Adulto, do Programa de PósGraduação em Processo de Desenvolvimento Humano e Saúde, da Universidade de Brasília, sob a docência da Profa. Dra. Maria Helena Fávero. O autor agradece a ela pelas preciosas colaborações na estruturação, discussão e revisão deste trabalho.

Doutorando do Programa de Pós-Graduação em Processo de Desenvolvimento Humano e Saúde, da Universidade de Brasília, bolsista da CAPES. 
Como ensina Ariès (1981), demorou muito até que se construísse o conceito de criança que se tem hoje. Determinadas circunstâncias históricas e sociais contribuíram com essa construção, a qual influenciou a emergência do conceito de adolescência, que, como sabemos, marcou o século XX. Na verdade, pode-se dizer que essa construção ocorreu e ocorre com os conceitos de idades da vida elaborados e reelaborados continuamente na nossa sociocultura, como bem demonstrou o referido historiador. Assim, nada mais previsível do que esperar o mesmo sobre a vida adulta.

Apesar da existência de teorias precursoras do desenvolvimento adulto oriundas de Bühler (1935) e Jung (Satude, 1995) no início do século passado, deve-se a Erik Erikson, na década de 1950, com seu trabalho titulado "Os oito estágios do homem", a realização dos primeiros estudos teóricos que ofereceram atenção à vida adulta, ligando dois ou mais estágios no desenvolvimento humano (Slater, 2003). Além de Erikson, ao longo da segunda metade do século XX outros teóricos, como Bee, Baltes, Gould e Levinson, constituíram teorias e metodologias fundamentais para 0 estudo do desenvolvimento da vida adulta (Bentley, 2007; Neri, 2006).

Como salientou Fávero (2007),

$\mathrm{Na}$ Psicologia do Desenvolvimento, o adulto certamente é o objeto mais recente. O desenvolvimento do adulto permaneceu muito tempo como um espaço vazio entre o desenvolvimento do adolescente e o do idoso. Os estudos sobre 0 envelhecimento trouxeram num primeiro tempo para a Psicologia, dois modelos teóricos para - estudo do adulto, ambos preocupados particularmente com a cognição. O primeiro modelo defendia a estabilidade cognitiva na fase adulta, enquanto 0 segundo defendia 0 decrescimento irreversível (ou com compensação) das capacidades cognitivas do adulto. Durante as últimas décadas, os limites desses modelos foram bem evidenciados e nós podemos hoje citar pelo menos três novas linhas para a abordagem do adulto: a de Baltes que propõe 0 conceito de "lifespan" (Baltes \& Standingers, 1996); a de Sinnot (1998), segundo a qual o sujeito adulto possui uma capacidade além do pensamento formal, o chamado pensamento pós-formal, o que corresponde a capacidade de pensar segundo diferentes sistemas do pensamento, e enfim, a abordagem de Young (1997) que se insere na perspectiva pós-moderna da Psicologia. Nós podemos tirar um consenso teórico dessas abordagens: o desenvolvimento do adulto apresenta fases e essas fases são caracterizadas pela união entre 0 aspecto cognitivo e o afetivo, entre o self e o outro. O adulto é, portanto, um construtor ativo de verdades múltiplas e polissêmicas: ser adulto significa estar em desenvolvimento no universo do desenvolvimento do pensamento coletivo. (p. 625-626 - traduzido por M. H. Fávero)

Em outros termos, ser adulto representa estar num meio de mediação semiótica. Do ponto de vista teórico, isso implica considerar as representações sociais, a linguagem e a semiótica, a fim de articulá-las com a Psicologia do Desenvolvimento. Além disso, tanto 0 conceito de adulto quanto os fenômenos relacionados a esse período acabam sendo polissêmicos na Psicologia do Desenvolvimento, não conseguindo nenhum conceito abordar plenamente o fenômeno de estudo.

Nesse sentido, foi criado um neologismo, parentalidade, para denotar a dissociação entre função e figura parental, ou seja, a figura parental de pai e mãe, devido às transformações ocorridas na sociedade referentes, inclusive, ao conceito de criança, as quais corresponderam a transformações equivalentes, embora não necessariamente simétricas, à função e ao conceito de pai/mãe, quer como casal parental, quer como gênero, quer como estágio de vida. Nesta direção é que foi proposto o termo curso de vida em substituição ao de ciclo de vida, conforme apontado acima.

Em vista destas perspectivas, nesta investigação parentalidade e generatividade são entendidas como fenômenos do ciclo de vida, aspectos eminentemente polissêmicos, que permitem fazer uma incursão na bibliografia nacional. Para tanto, antes da descrição do nosso método, retomamos Erikson. 


\section{PARENTALIDADE: GENERATIVIDADE VERSUS ESTAGNAÇÃO}

Erikson (1950/1976, $1968 / 1972)$,
originariamente, foi seguidor do modelo
psicossexual freudiano, mas depois discordou
dessa perspectiva e propôs um desenvolvimento positivo, ligado às crises normativas que ocorrem ao longo de toda a vida. Para 0 autor, essas crises eram fomentadas pelo contexto no qual a pessoa está inserida. Devido à atenção especial ao fator ambiental no desenvolvimento, por vezes sua teoria foi denominada de Teoria do Desenvolvimento Psicossocial (Bentley, 2007).

O sétimo estágio de sua teoria - que compreende 0 adulto de meia-idade representa o grande conflito da vida adulta (Slater, 2003). Esse estágio, qualificado por Erikson (1968/1972) como generatividade versus estagnação, representa o período em que a pessoa avalia o que realizou na vida até aquele momento e o pretende deixar à posteridade em termos de produção ou constituição de bens e de manutenção da humanidade pelo cuidado de outras pessoas.

O aspecto principal desse período é a percepção da pessoa sobre o que é a vida, o que essa pessoa realizou ao longo dela, quais metas foram atingidas e como se pode contribuir para melhorar o mundo (Bentley, 2007). Assim, a generatividade se direciona para além do círculo familiar, considerando a sociedade e as gerações futuras. Apesar de Erikson ter delimitado essa fase ao adulto de meia-idade, ela pode ser identificada em várias fases do desenvolvimento humano (Hart, Southerland \& Atkins, 2003; Slater, 2003). Quando a generatividade é alcançada assevera Erikson (1968/1972) - a pessoa descobre a possibilidade de construir diretrizes claras para a vida sobre o que deve e não deve ser feito, tornando-se não só mais feliz, mas também capaz de viver uma vida produtiva (Rothrauff \& Cooney, 2008).

Afirma Erikson (1968/1972) que, para resolução de parte da crise dessa fase, a parentalidade surge como uma eficaz estratégia para cuidar de alguém, seja um filho seja outra pessoa, contribuindo para o futuro (Rothrauff \& Cooney, 2008). É relevante destacar que, apesar de a paternidade e a maternidade poderem estar inseridas na parentalidade, esta está além de ser pai ou mãe. O estudo de Bronfenbrenner (2011), por exemplo, que objetivou pesquisar o estado da parentalidade estadunidense, constatou que cada vez mais as pessoas pensam em si e desprezam as necessidades dos outros, considerando que ter e criar um filho é uma escolha pessoal e não afetará ninguém.

Tomando como base esses conceitos, a presente pesquisa objetivou realizar uma revisão da literatura em periódicos nacionais relacionados à parentalidade. Como ao se iniciar esta pesquisa foi constatado que as publicações eram escassas na Psicologia, optou-se por não estipular um intervalo de tempo para se poder resgatar a maior quantidade possível de linhas de pesquisa e contribuições teórico-metodológicas sobre esse objeto.

\section{MÉTODO}

\section{Procedimento de coleta}

A revisão da literatura nacional ocorreu durante o mês de janeiro de 2011, mediante busca eletrônica nas bases de dados, Scientific Electronic Library Online [SciELO, http://www.scielo.org/], o Index Psi Periódicos [IndexPsi, http://www.bvs-psi.org.br/] e 0 Periódicos Eletrônicos em Psicologia [PePSIC, http://pepsic.bvsalud.org/]. A escolha desses indexadores ocorreu por serem eles os que abrangem o maior número de produções nacionais (artigos completos e resumos) na área da Psicologia.

Até a data desta revisão o PePSIC era composto por 84 periódicos em Psicologia, principalmente do Brasil, todos com textos completos e de acesso gratuito. O número de revistas indexadas era de 753 no SciELO, sendo estas de diversas áreas e nacionalidades. Seu acesso, assim como no PePSIC, também era gratuito, e os artigos neles indexados estavam na íntegra.

As revistas científicas e não científicas, exclusivamente de Psicologia, pertencentes ao IndexPsi, totalizavam 186. Destas, 116 estavam com publicação corrente, 23 tiveram sua indexação interrompida em 2010 e 47 findaram a edição de novos volumes. Como nesse indexador o acesso às produções era especialmente pelos resumos, enquanto os textos completos foram adquiridos via acervo 
da Biblioteca Central da Universidade de Brasília (BCE/UnB) e o acesso ao website da revista. Quando o periódico não era localizado nesses locais, fazia-se contato com o editor do periódico ou com os autores dos artigos por trocas de e-mail.

As consultas a essas bases de dados cobriram todas as publicações existentes até o momento desta revisão, sendo utilizadas como descritores as palavras parentalidade e seu equivalente em inglês parenthood. A amostra compreendeu somente as produções de artigos completos, selecionados pela leitura prévia dos seus resumos, sendo excluídos: (a) artigos que se repetissem nas bases de dados; (b) produções de revistas de divulgação científica; (c) teses, dissertações, trabalhos de conclusão de curso, relatórios, livros e capítulos de livros; (d) investigações publicadas em periódicos internacionais; e, finalmente, (e) textos que não tivessem relação com a Psicologia.

\section{Procedimento de análise}

A partir da leitura de cada artigo, estabeleceu-se uma hierarquização das seguintes informações das produções: (a) base de dados; (b) avaliação Qualis de 2012 da revista na Psicologia; (c) ano de publicação; (d) método empregado; (e) população pesquisada (sexo, faixa etária, escolaridade e etnia); (f) sexo do primeiro autor; (g) periódico; e (h) área de concentração na Psicologia. A leitura dos artigos permitiu elaborar categorias conforme a análise teórico-metodológica de seu conteúdo.

A sistematize dessa análise foi exposta em tabelas como propuseram Fávero e Souza (2001). A primeira e a segunda colunas dessas tabelas fornecem a identificação das referências pelo nome do primeiro autor e da revista que ele publicou; a terceira apresenta o referencial teórico utilizado; a quarta, os objetivos principais da investigação; a quinta identifica o método utilizado; e a sexta mostra os principais resultados e conclusões descritos.

\section{RESULTADOS}

Quanto aos aspectos quantitativos, no total foram localizadas 58 produções sobre parentalidade nos indexadores pesquisados (36\% do PePSIC, $32 \%$ do SciELO e $32 \%$ do IndexPsi). Após a leitura dos estudos e a exclusão de algumas produções, segundo os critérios previamente scritosno método, foram identificados 32 artigos científicos $(50 \%$ do PePSIC, $31 \%$ do SciELO e $19 \%$ do IndexPsi), distribuídos em 26 periódicos.

Dessas 26 revistas que publicaram algum artigo sobre parentalidade, a Revista Brasileira de Psicanálise (Qualis, B1) foi a que apresentou mais produções, com três artigos. Cinco outras revistas - Psicologia em Estudo (Qualis, A2), Psicologia Clínica (Qualis, B1), Revista Brasileira do Crescimento e Desenvolvimento Humano (Qualis, B1), Aletheia (Qualis, B2), Boletim de Psicologia (Qualis, B2) - publicaram apenas dois artigos cada. As demais 19 revistas publicaram, até o período desta revisão, apenas um artigo cada.

Pelo levantamento se constatou que as duas primeiras produções sobre parentalidade indexadas datam de 2001, ambas direcionadas à Psicologia Clínica na perspectiva psicodinâmica (Benghozi, 2001; Lowenkron, 2001). $\mathrm{Na}$ distribuição de produções ao longo do tempo, somente após a segunda metade da década passada - de 2001 até 2005 - foi que o número de produções aumentou, sendo sete o número de trabalhos que foram publicados, número equivalente ao total de produções de 2006. Nos dois anos seguintes a quantidade de produções foi estável $(2007, f=8$ e $2008, f=6)$, caindo somente nos anos finais deste levantamento $(2009, f=3$ e $2010, f=1)$.

Dentre as áreas de investigação da Psicologia, a Psicologia Clínica $(f=16,50 \%)$ foi a que concentrou mais produções, sendo a Psicanálise a teoria mais utilizada $(f=8)$. Após a Psicologia Clínica, a Psicologia do Desenvolvimento foi a que apresentou mais produções $(f=7,21,9 \%)$, seguida pela Psicologia Social $(f=4,12,5 \%)$, Psicologia da Saúde $(f=2,6,3 \%)$, Psicologia Escolar e Educacional $(f=2,6,3 \%)$ e Psicologia Jurídica $(f=1,3,1 \%)$.

Quanto ao sexo dos autores, as mulheres foram as que mais pesquisaram esse fenômeno ( $f=27,84,4 \%)$. Metodologicamente, apenas uma investigação adotou o modelo longitudinal e uma a revisão da literatura. 
Ocorreu quase uma isonomia na distribuição das produções teóricas e empíricas: os estudos empíricos somaram $17(53,1 \%)$ e os de compreensão teórica equivaleram a 14 $(43,8 \%)$. Nos estudos empíricos, 14 eram qualitativos, dois quantitativos e um quantiqualitativos.

Seguindo-se a orientação conceitual de Erikson (1950/1976) sobre os oito estágios do desenvolvimento humano, dividiu-se a faixa etária dos participantes dos estudos empíricos revisados. Aglutinaram-se apenas as quatro primeiras fases, pelo fato de as idades serem muito próximas. Assim, os participantes foram divididos em crianças (um até cinco anos), adolescentes (12 a 20 anos), adultos jovens (20 a 39 anos), adultos de meia-idade (40 a 64 anos) e adultos idosos (acima de 65 anos).

Quatro $(23,5 \%)$ dos artigos pesquisados tinham na sua amostra, exclusivamente, jovens adultos e adultos de meia-idade. Três $(17,6 \%)$ deles tinham apenas adultos de meiaidade, um (5,9\%) apenas crianças, um $(5,9 \%)$ apenas adolescente e um (5,9\%), apenas jovens adultos, adultos de meia-idade $e$ idosos. O sexo da amostra ficou distribuído como segue: quatro $(23,5 \%)$ optaram por ter uma quantidade igualitária entre homens e mulheres, a mesma quantidade de investigações $(23,5 \%)$ optaram por ter mais mulheres do que homens. Cinco pesquisas $(29,4 \%)$ constituíram sua amostra apenas por mulheres, enquanto dois estudos $(11,8 \%)$ a formaram apenas por homens; também duas pesquisas $(11,8 \%)$ tiveram em sua amostra mais homens do que mulheres.

Identificou-se, assim, que a maior parte desses participantes estava na vida adulta, com idades entre 20 e 64 anos, existindo também, no total das amostras, mais mulheres como respondentes do que homens. Mais de um quarto dos estudos não especificou a faixa etária dos participantes. Além disso, somente dois estudos indicaram a preferência sexual dos seus participantes, e nenhum indicou a etnia. A classe social foi apresentada por três dos estudos empíricos e apenas cinco indicaram o nível de escolaridade da amostra.

Apesar de algumas investigações encontradas na revisão poderem estar presentes em mais de uma categoria de conteúdo (v.g., Furtino \& Martins, 2006), optou-se pela inclusão do artigo naquela que melhor qualificasse a produção dentro de seus objetivos, tese, referencial teórico, revisão da literatura e resultados. Nossa análise evidenciou cinco categorias de publicações sobre o tema em questão: (a) a Parentalidade na adoção ( $f=5,15,6 \%)$; (b) a Parentalidade em contextos adversos ( $\mathrm{f}=7,21,9 \%)$; (c) a Parentalidade homoafetiva ( $\mathrm{f}=3,9,4 \%) ;(\mathrm{d})$ as Relações de gênero na parentalidade $(\mathfrak{f}=7$, 21,9\%); (e) a Parentalidade na transição de vida $(\mathrm{f}=10,31,2 \%)$.

$\mathrm{Na}$ categoria Parentalidade na adoção foram incluídos os estudos que buscavam compreender o fenômeno da parentalidade com filhos adotivos ou a busca da efetivação da parentalidade pela adoção. Como se pode observar na tabela 1, a característica fundamental dessa categoria é o entendimento sistêmico ou sociológico do fenômeno, buscando-se descrevê-lo e compreendê-lo.

Pode-se asseverar ainda, sobre a categoria Parentalidade na adoção, que os trabalhos que a integram têm a tese consensual da dificuldade da adoção para casais hetero e homossexuais por dificuldades socioculturais, ocasionando desmotivação para adoção. Além disso, percebe-se a necessidade de melhor compreender a intra e intersubjetividade de quem quer adotar, para o bom estabelecimento das relações com o filho adotado (cfr., Tabela 1). 
Tabela 1. Categoria: parentalidade na adoção

\begin{tabular}{|c|c|c|c|c|c|}
\hline $\begin{array}{l}\text { Primeiro } \\
\text { autor }\end{array}$ & Periódico & $\begin{array}{l}\text { Referencial } \\
\text { teórico }\end{array}$ & Objetivos & Método & Resultados \\
\hline $\begin{array}{l}\text { Ana Karen } \\
\text { Gondim } \\
\text { (2008) }\end{array}$ & Bol. psicol. & $\begin{array}{l}\text { Familiar } \\
\text { Sistêmica de } \\
\text { Costa e Wagner }\end{array}$ & $\begin{array}{l}\text { Identificar os motivos que } \\
\text { levaram e levam pais a } \\
\text { decidirem pelo processo de } \\
\text { adoção. }\end{array}$ & $\begin{array}{l}\text { Qualitativo: entrevista semiestruturada } \\
\text { com } 8 \text { mulheres e } 2 \text { homens com idade } \\
\text { entre } 20 \text { e } 69 \text { anos, com escolaridade } \\
\text { entre o ensino fundamental incompleto e } \\
\text { pós-graduação. }\end{array}$ & $\begin{array}{l}\text { Os resultados mostraram que o processo de } \\
\text { adoção apresenta dificuldades, preconceitos, } \\
\text { falta de acompanhamento psicológico o que } \\
\text { age geram empecilho ou desmotivação. }\end{array}$ \\
\hline $\begin{array}{l}\text { Livia K. } \\
\text { Otuka } \\
\text { (2009) }\end{array}$ & $\begin{array}{l}\text { Bras. } \\
\text { crescimento } \\
\text { desenvolv. } \\
\text { hum. }\end{array}$ & $\begin{array}{l}\text { Familiar } \\
\text { Sistêmica de } \\
\text { Féres-Carneiro }\end{array}$ & $\begin{array}{l}\text { Atualizar a literatura latino- } \\
\text { americano sobre adoção. }\end{array}$ & Revisão da literatura (período: 1998-2008). & $\begin{array}{l}\text { Os artigos recuperados abordam a construção } \\
\text { de vínculos na adoção, porém poucos } \\
\text { abordam as relações fraternas na família. }\end{array}$ \\
\hline $\begin{array}{l}\text { Manoel A. } \\
\text { Santos } \\
(2003)\end{array}$ & Psic. & $\begin{array}{l}\text { Sociológica de } \\
\text { Schettini Filho }\end{array}$ & $\begin{array}{l}\text { Compreender a } \\
\text { parentalidade do casal } \\
\text { adotivo e avaliar seus } \\
\text { recursos e da criança } \\
\text { adotada. }\end{array}$ & $\begin{array}{l}\text { Quantiquali: amostra formada por uma } \\
\text { família composta por pai com } 45 \text { anos e } \\
\text { mãe com } 40 \text { anos e } 2 \text { crianças do sexo } \\
\text { masculino, de } 6 \text { e } 10 \text { anos. Foram } \\
\text { realizadas entrevista semiestruturada, } \\
\text { aplicação de testes e escalas com os } \\
\text { adultos; com as crianças foram aplicados } \\
\text { testes e escalas. }\end{array}$ & $\begin{array}{l}\text { 1. Indicou-se que a motivação para a adoção } \\
\text { foi a infertilidade de ambos os pais; } \\
\text { 2. Identificou-se que as adoções foram tardias, } \\
\text { o que se distancia do perfil típico dos } \\
\text { processos brasileiros; } \\
\text { 3. Identificou-se que crianças mostram perfis } \\
\text { contrastantes na tentativa de se adaptarem às } \\
\text { expectativas parentais e ambientais. }\end{array}$ \\
\hline $\begin{array}{l}\text { Regina S. } \\
\text { Futino } \\
(2006)\end{array}$ & Aletheia & $\begin{array}{l}\text { Sociológica de } \\
\text { Fry e MacRae }\end{array}$ & $\begin{array}{l}\text { Compreender a adoção e a } \\
\text { homoparentalidade na } \\
\text { modernidade. }\end{array}$ & Estudo teórico. & $\begin{array}{l}\text { Compreende-se que o pressuposto que o } \\
\text { homossexual não pode e não quer ter filhos } \\
\text { perde sua força, sendo os impedimentos mais } \\
\text { morais do que legais. }\end{array}$ \\
\hline $\begin{array}{l}\text { Suzana S. } \\
\text { M. Schettini } \\
(2006)\end{array}$ & Psicol. estud. & $\begin{array}{l}\text { Psicodinâmica de } \\
\text { Freud e Dolto }\end{array}$ & $\begin{array}{l}\text { Compreender a paternidade } \\
\text { adotiva na constituição da } \\
\text { identidade dos pais. }\end{array}$ & Estudo teórico. & $\begin{array}{l}\text { Compreendeu-se a necessidade dos } \\
\text { candidatos a pais entenderem sua dinâmica } \\
\text { para estabelecer parâmetros de uma relação } \\
\text { saudável com os futuros filhos. }\end{array}$ \\
\hline
\end{tabular}

A segunda categoria abarcou os trabalhos que focavam a experiência da Parentalidade em contextos adversos, como pobreza, situação de doença terminal, violência ou em privação de liberdade. Constituídos essencialmente por estudos qualitativos das perspectivas sistêmica e psicodinâmica (cfr., Tabela 2), eles possuem como aspecto comum as dificuldades da parentalidade na relação pai e filho relacionadas a contextos não promotores do desenvolvimento positivo.

Tabela 2. Categoria: parentalidade em contextos adversos

\begin{tabular}{|c|c|c|c|c|c|}
\hline $\begin{array}{l}\text { Primeiro } \\
\text { autor }\end{array}$ & Periódico & $\begin{array}{l}\text { Referencial } \\
\text { teórico }\end{array}$ & Objetivos & Método & Resultados/Conclusões \\
\hline $\begin{array}{l}\text { Janete } \\
\text { Márcia W. } \\
\text { Lazzari } \\
\text { (2008) }\end{array}$ & Aval. psicol. & $\begin{array}{l}\text { Psicodiagnóstico } \\
\text { de Cunha }\end{array}$ & $\begin{array}{l}\text { Investigar a percepção dos pais } \\
\text { sobre a mudança de } \\
\text { comportamento dos filhos após o } \\
\text { processo psicodiagnóstico. }\end{array}$ & $\begin{array}{l}\text { Qualitativo: entrevista } \\
\text { semiestruturada com } 13 \text { mães com } \\
\text { idade entre } 27 \text { e } 53 \text { anos, com nível } \\
\text { socioeconômico e cultural baixos, } \\
\text { sendo a maioria de nível médio e } \\
\text { fundamental incompleto. }\end{array}$ & $\begin{array}{l}\text { 1. Maior rendimento, responsabilidade e } \\
\text { organização nas atividades escolares dos } \\
\text { filhos foram identificados; } \\
\text { 2. Melhor expressão de vínculo afetivo entre } \\
\text { pais e filhos como diminuição da ansiedade e } \\
\text { agressividade foram também percebidos. }\end{array}$ \\
\hline $\begin{array}{l}\text { Laura A. } \\
\text { Bem (2006) }\end{array}$ & Psicol. estud. & $\begin{array}{l}\text { Ecológico- } \\
\text { Sistêmica de } \\
\text { Bronfenbrenner }\end{array}$ & $\begin{array}{l}\text { Descrever fatores envolvidos no } \\
\text { processo de escolha das } \\
\text { estratégias educativas utilizadas } \\
\text { por pais e mães de famílias de } \\
\text { baixo nível socioeconômico. }\end{array}$ & Estudo teórico. & $\begin{array}{l}\text { 1. Identificam-se os conceitos de valores, } \\
\text { metas e práticas educativas e descreve suas } \\
\text { interconexões; } \\
\text { 2. Identifica-se a forma de pensar e de } \\
\text { promover o desenvolvimento e a educação } \\
\text { das crianças. }\end{array}$ \\
\hline $\begin{array}{l}\text { Maria } \\
\text { Angela M. } \\
\text { Yunes } \\
(2007)\end{array}$ & $\begin{array}{l}\text { Psicol. reflex. } \\
\text { crit }\end{array}$ & $\begin{array}{l}\text { Sistêmica de } \\
\text { Bronfenbrenner e } \\
\text { Rutter }\end{array}$ & $\begin{array}{l}\text { Comparar as crenças de agentes } \\
\text { comunitários de saúde sobre a } \\
\text { resiliência de famílias } \\
\text { monoparentais e de baixa renda } \\
\text { e suas estratégias de } \\
\text { enfrentamento. }\end{array}$ & $\begin{array}{l}\text { Qualitativo: entrevista } \\
\text { semiestruturada com } 3 \text { agentes de } \\
\text { saúde mulheres e } 1 \text { homem. }\end{array}$ & $\begin{array}{l}\text { Identificam-se crenças pessimistas dos } \\
\text { agentes comunitários sobre o funcionamento } \\
\text { das famílias pobres, em contraposição aos } \\
\text { fatores indicativos de resiliência constatados } \\
\text { nas histórias de vida destas famílias. }\end{array}$ \\
\hline $\begin{array}{l}\text { Mônica F. } \\
\text { Silva (2007) }\end{array}$ & $\begin{array}{l}\text { Bras. } \\
\text { crescimento } \\
\text { desenvolv. } \\
\text { hum. }\end{array}$ & $\begin{array}{l}\text { Bioecológica de } \\
\text { Bronfenbrenner }\end{array}$ & $\begin{array}{l}\text { Compreender a relação entre } \\
\text { pais presidiários e seus filhos, no } \\
\text { ambiente prisional. }\end{array}$ & $\begin{array}{l}\text { Qualitativo: entrevista } \\
\text { semiestruturada com } 7 \text { pais presos. }\end{array}$ & $\begin{array}{l}\text { Indicam que a prisão gera impactos na relação } \\
\text { pai e filho e a instituição não está preparada } \\
\text { para lidar com essa questão. }\end{array}$ \\
\hline $\begin{array}{l}\text { Patrícia L. } \\
\text { Moreira } \\
\text { (2008) }\end{array}$ & $\begin{array}{l}\text { Rev. latino-am. } \\
\text { enfermagem }\end{array}$ & $\begin{array}{l}\text { Interacionismo } \\
\text { Simbólico de } \\
\text { Charon }\end{array}$ & $\begin{array}{l}\text { Compreender a experiência de } \\
\text { tornar-se mãe de uma criança } \\
\text { com câncer. }\end{array}$ & $\begin{array}{l}\text { Qualitativo: entrevista } \\
\text { semiestruturada com } 7 \text { mães de } \\
\text { crianças com câncer com idade } \\
\text { entre } 24 \text { e } 42 \text { anos. }\end{array}$ & $\begin{array}{l}\text { Revela-se que o papel de mãe é construído } \\
\text { numa conjugação entre (a) viver o tempo da } \\
\text { doença e (b) viver o tempo de luta pela vida da } \\
\text { criança. }\end{array}$ \\
\hline $\begin{array}{l}\text { Pierre } \\
\text { Benghozi } \\
(2001)\end{array}$ & Psicol. clín. & $\begin{array}{l}\text { Psicodinâmica de } \\
\text { Freud }\end{array}$ & $\begin{array}{l}\text { Compreender a autoridade } \\
\text { parental legítima, segundo a } \\
\text { concepção psicanalítica do laço. }\end{array}$ & Estudo teórico. & $\begin{array}{l}\text { Explicita-se os segredos familiares na } \\
\text { construção do laço e a referência à lei nas } \\
\text { famílias incestuosas. }\end{array}$ \\
\hline $\begin{array}{l}\text { Rute S. } \\
\text { Maltz } \\
(2008) \\
\end{array}$ & $\begin{array}{l}\text { Rev. bras. } \\
\text { psicanál. }\end{array}$ & $\begin{array}{l}\text { Psicodinâmica de } \\
\text { Freud e Klein }\end{array}$ & $\begin{array}{l}\text { Estudo relacionando poder } \\
\text { parental com filicídio. }\end{array}$ & Estudo teórico. & $\begin{array}{l}\text { A relação saber e poder enriquece o } \\
\text { entendimento deste complexo problema. }\end{array}$ \\
\hline
\end{tabular}


A Parentalidade homoafetiva direciona a compreensão da parentalidade promovida por homens e/ou mulheres homossexuais. Essa categoria tem por princípio fundamental o foco na homoparentalidade e discute especificidades dessa prática conjugal no atual contexto sociocultural, como constatado na tabela 3.
Enquanto tese consensual, os três artigos dessa categoria focam a homofobia e o pouco apoio social e afetivo para esse tipo de parentalidade; mas os estudos legitimam a homoparentalidade, considerando-a como uma relação conjugal semelhante à heteroparenatlidade.

Tabela 3. Categoria: parentalidade homoafetiva

\begin{tabular}{|c|c|c|c|c|c|}
\hline $\begin{array}{l}\text { Primeiro } \\
\text { autor }\end{array}$ & Periódico & Referencial teórico & Objetivos & Método & Resultados/Conclusões \\
\hline $\begin{array}{l}\text { Anna P. } \\
\text { Uziel (2006) }\end{array}$ & $\begin{array}{l}\text { Horiz. } \\
\text { antropol. }\end{array}$ & $\begin{array}{l}\text { Sociológica de } \\
\text { Grossi }\end{array}$ & $\begin{array}{l}\text { Entender como a conjugalidade e a } \\
\text { parentalidade ocorrem. }\end{array}$ & $\begin{array}{l}\text { Qualitativo: entrevistas com } 10 \\
\text { homens homossexuais. }\end{array}$ & $\begin{array}{l}\text { 1. Observou-se: a parceria civil é vista } \\
\text { como tema aglutinador; } \\
\text { 2. A homofobia é um tema central. }\end{array}$ \\
\hline $\begin{array}{l}\text { Brunella C. } \\
\text { Rodriguez } \\
\text { (2009) }\end{array}$ & Vínculo & $\begin{array}{l}\text { Psicodinâmico de } \\
\text { Winnicott e } \\
\text { Roudinesco }\end{array}$ & $\begin{array}{l}\text { Investigar o exercício da } \\
\text { homoparentalidade, focando as possíveis } \\
\text { especificidades existentes no } \\
\text { relacionamento parental homossexual, bem } \\
\text { como compreender o olhar dos pais com } \\
\text { relação a seus papéis parentais. }\end{array}$ & \begin{tabular}{|l|} 
Qualitativo-clínico: entrevistas \\
semidirigidas, aplicação de testes e \\
registros de campo com dois casais \\
homoparentais, um de mulheres e \\
outro de homens com idade entre \\
25 e 40 anos.
\end{tabular} & $\begin{array}{l}\text { 1. As famílias homoparentais se } \\
\text { diferenciam de outras pelo } \\
\text { preconceito e falta de apoio das } \\
\text { famílias de origem e sociedade; } \\
\text { 2. As famílias homoparentais } \\
\text { possuem especificidades como } \\
\text { qualquer outra família. }\end{array}$ \\
\hline $\begin{array}{l}\text { Simone } \\
\text { Perelson } \\
\text { (2006) }\end{array}$ & $\begin{array}{l}\text { Rev. } \\
\text { estud. fem. }\end{array}$ & \begin{tabular}{|l|} 
Psicodinámicos de \\
Dor, Legendre, Tort, \\
Parseval e Prokhoris
\end{tabular} & $\begin{array}{l}\text { Debater a homoparentalidade no contexto } \\
\text { das novas práticas sociais e médicas } \\
\text { referentes à filiação e à reprodução. }\end{array}$ & Estudo teórico. & $\begin{array}{l}\text { Legitima-se, pela perspectiva } \\
\text { psicodinâmica, à filiação } \\
\text { homossexual. }\end{array}$ \\
\hline
\end{tabular}

Formada por seis investigações, conforme a tabela 4, a categoria Relações de gênero na parentalidade refere-se à importância da divisão igualitária de atributos da parentalidade. Numa perspectiva que privilegia as teorias psicodinâmicas, ela tem como aspecto principal perceber como homens e mulheres veem a parentalidade, considerando os papéis que se estabelecem nessa função.

Tabela 4. Categoria: relações de gênero na parentalidade

\begin{tabular}{|c|c|c|c|c|c|}
\hline \begin{tabular}{|l|} 
Primeiro \\
autor
\end{tabular} & Periódico & \begin{tabular}{|l|}
$\begin{array}{l}\text { Referencial } \\
\text { teórico }\end{array}$ \\
\end{tabular} & Objetivos & Método & Resultados/Conclusões \\
\hline $\begin{array}{l}\text { Áurea M. } \\
\text { Lowenkron } \\
(2001)\end{array}$ & $\begin{array}{l}\text { Rev. bras. } \\
\text { psicanál }\end{array}$ & $\begin{array}{l}\text { Psicodinâmica de } \\
\text { Freud }\end{array}$ & $\begin{array}{l}\text { Enfatizar as mudanças da } \\
\text { contemporaneidade com parentesco } \\
\text { e filiação como focaliza dois tipos de } \\
\text { situação de monoparentalidade } \\
\text { materna. }\end{array}$ & Estudo teórico. & $\begin{array}{l}\text { Levanta-se questões sobre a relação entre a } \\
\text { teoria psicanalítica e as transformações } \\
\text { socioeconômicas, tecnológicas e de valores } \\
\text { na contemporaneidade. }\end{array}$ \\
\hline $\begin{array}{l}\text { Durval L. Faria } \\
\text { (2007) }\end{array}$ & Bol. psicol. & $\begin{array}{l}\text { Psicologia } \\
\text { Analítica de Jung }\end{array}$ & \begin{tabular}{|l|} 
Refletir sobre a paternidade de filhos \\
adolescentes a crise do meio da vida \\
e a individuação masculina.
\end{tabular} & $\begin{array}{l}\text { Qualitativo: grupo clínico constituído } \\
\text { por } 5 \text { homens adultos pais. }\end{array}$ & $\begin{array}{l}\text { Os conflitos podem ser um instrumento de } \\
\text { elaboração do papel de pai pela relação } \\
\text { passada pai-filho. }\end{array}$ \\
\hline $\begin{array}{l}\text { Eliane P. } \\
\text { Vargas (2010) }\end{array}$ & $\begin{array}{l}\text { Cad. saúde } \\
\text { pública }\end{array}$ & $\begin{array}{l}\text { Sociologia da } \\
\text { Sexualidade de } \\
\text { Bozon }\end{array}$ & $\begin{array}{l}\text { Analisar aspectos constitutivos da } \\
\text { dinâmica sexual conjugal moderna } \\
\text { entre casais de orientação } \\
\text { heterossexual. }\end{array}$ & $\begin{array}{l}\text { Qualitativo: estudo etnográfico com } \\
7 \text { casais heterossexual, } 2 \text { casais de } \\
\text { mulheres, } 1 \text { mulher separada e } 1 \\
\text { solteira, a maioria de casse média } \\
\text { de nível superior. }\end{array}$ & $\begin{array}{l}\text { Evidenciam-se aspectos divergente da } \\
\text { vivência da parentalidade: o filho como } \\
\text { resultado "natural" e o filho de escolha } \\
\text { racional; }\end{array}$ \\
\hline $\begin{array}{l}\text { José Augusto } \\
\text { E. Hernandez } \\
(2008)\end{array}$ & $\begin{array}{l}\text { Psic.: teor. } \\
\text { e pesq. }\end{array}$ & $\begin{array}{l}\text { Esquemas de } \\
\text { Gênero de Bem }\end{array}$ & \begin{tabular}{|l|} 
Investigar as relações entre papéis \\
sexuais, ajustamento conjugal e \\
emocional de mulheres no período da \\
gravidez.
\end{tabular} & $\begin{array}{l}\text { Quantitativo: survey com } 135 \\
\text { mulheres gestantes com idade } \\
\text { entre } 16 \text { e } 40 \text { anos, a maioria com } \\
\text { nível médio. }\end{array}$ & $\begin{array}{l}\text { Evidenciam-se relações significativas entre } \\
\text { papéis sexuais e ajustamento conjugal. }\end{array}$ \\
\hline $\begin{array}{l}\text { Juliana } \\
\text { Perucchii } \\
(2007)\end{array}$ & Psicol. clin. & $\begin{array}{l}\text { Sócio histórico de } \\
\text { Vygotsky }\end{array}$ & $\begin{array}{l}\text { Investigar concepções que mulheres } \\
\text { chefes de família têm sobre a } \\
\text { paternidade. }\end{array}$ & $\begin{array}{l}\text { Qualitativo: entrevista } \\
\text { semiestruturada com } 10 \text { mães não } \\
\text { casadas com mais de } 30 \text { anos e } \\
\text { com, no mínimo, ensino médio } \\
\text { incompleto. }\end{array}$ & $\begin{array}{l}\text { As concepções dessas mulheres sobre a } \\
\text { parentalidade e relações de gênero } \\
\text { perpassam suas vivências e experiências } \\
\text { familiar. }\end{array}$ \\
\hline $\begin{array}{l}\text { Maria C. } \\
\text { Passos (2007) }\end{array}$ & Mental & $\begin{array}{l}\text { Psicodinâmica de } \\
\text { Freud e } \\
\text { Roudinesco } \\
\end{array}$ & $\begin{array}{l}\text { Discutir a constituição dos laços } \\
\text { afetivos na família na } \\
\text { contemporaneidade. }\end{array}$ & Estudo teórico. & $\begin{array}{l}\text { Conclui-se a necessidade de uma } \\
\text { perspectiva mais flexível para além do } \\
\text { modelo patriarcal familiar. }\end{array}$ \\
\hline $\begin{array}{l}\text { Renata de F. } \\
\text { Brasileiro } \\
(2002)\end{array}$ & Psico & $\begin{array}{l}\text { Psicodinâmica de } \\
\text { Roudinesco }\end{array}$ & $\begin{array}{l}\text { Discutir temas relativos ao modo } \\
\text { como é vivida a transição para a } \\
\text { parentalidade. }\end{array}$ & Estudo teórico. & $\begin{array}{l}\text { 1. Os homens são mais liberais em atitudes } \\
\text { do que comportamentos; } \\
\text { 2. As mulheres tem tendência para } \\
\text { diferenciação nos papéis de gênero de } \\
\text { acordo com antigos estereótipos quanto ao } \\
\text { lugar/função de homens e de mulheres. }\end{array}$ \\
\hline
\end{tabular}

Os estudos dessa categoria possuem como tese consensual que o exercício da parentalidade perpassa previamente as experiências pessoais e familiares de homem e mulher e a interferência do contexto sociocultural. Aspectos da monoparentalidade são destacados, estando os estereótipos e valores, apesar de contestados, ainda 
presentes no exercício da parentalidade (cfr. tabela 4).

Finalmente, além de ser a categoria com mais estudos (cfr. tabela 5), a Parentalidade na transição de vida é também a que reúne mais investigações de referencial psicodinâmico. Nos estudos empíricos essa categoria foi a que apresentou maior diversidade na amostra quanto à faixa etária e ao grau de instrução. A característica essencial dessa categoria é analisar e compreender a dinâmica das relações bidirecionais ou unidirecionais da díade pai-filho ou da mãe-filho e da transição para a parentalidade considerando aspectos sociais, culturais, econômicos e relacionais.

Tabela 5. Categoria: Parentalidade na transição de vida

\begin{tabular}{|c|c|c|c|c|c|}
\hline $\begin{array}{l}\text { Primeiro } \\
\text { autor }\end{array}$ & Periódico & Referencial teórico & Objetivos & Método & Resultados/Conclusões \\
\hline $\begin{array}{l}\text { Clarissa C. } \\
\text { Menezes } \\
(2007)\end{array}$ & Bol. psicol. & $\begin{array}{l}\text { Familiar Sistêmica } \\
\text { de Minuchin }\end{array}$ & $\begin{array}{l}\text { Analisar a relação conjugal, } \\
\text { durante a transição para a } \\
\text { parentalidade. }\end{array}$ & $\begin{array}{l}\text { Qualitativo: estudo de caso } \\
\text { longitudinal com } 4 \text { casais } \\
\text { com idade de } 20 \text { anos. }\end{array}$ & $\begin{array}{l}\text { A compreensão da conjugalidade na } \\
\text { transição para a parentalidade é a } \\
\text { qualidade da relação conjugal anterior. }\end{array}$ \\
\hline $\begin{array}{l}\text { Fermín R. } \\
\text { Navarro } \\
(2007) \\
\end{array}$ & Cienc. psicol. & Apego de Bowlby & $\begin{array}{l}\text { Compreender as influência e } \\
\text { dificuldade da parentalidade } \\
\text { como da vinculação pai-filho. }\end{array}$ & Estudo teórico. & $\begin{array}{l}\text { A mediação familiar é uma forma de } \\
\text { resolução dos conflitos. }\end{array}$ \\
\hline $\begin{array}{l}\text { François } \\
\text { Marty (2004) }\end{array}$ & Psicanálise & $\begin{array}{l}\text { Psicodinâmica de } \\
\text { Freud }\end{array}$ & $\begin{array}{l}\text { Analisar os laços afetivos } \\
\text { entre pais e filhos. }\end{array}$ & Estudo teórico. & $\begin{array}{l}\text { A identificação à função parental, a saída } \\
\text { da adolescência e a entrada no mundo } \\
\text { adulto. }\end{array}$ \\
\hline $\begin{array}{l}\text { Geraldo M. } \\
\text { Carvalho } \\
(2009)\end{array}$ & $\begin{array}{l}\text { Texto contexto } \\
\text { - enferm. }\end{array}$ & $\begin{array}{l}\text { Sociologia } \\
\text { Fenomenológica de } \\
\text { Schütz }\end{array}$ & $\begin{array}{l}\text { Estudar a percepção de } \\
\text { adolescentes sobre a } \\
\text { parentalidade. }\end{array}$ & $\begin{array}{l}\text { Qualitativo: entrevistas com } \\
5 \text { pais e } 10 \text { mães com idade } \\
\text { entre } 10 \text { e } 20 \text { anos. }\end{array}$ & $\begin{array}{l}\text { A parentalidade adolescente é um } \\
\text { fenômeno complexo, cujas diversas } \\
\text { vivências dependem do contexto social. }\end{array}$ \\
\hline $\begin{array}{l}\text { Leila M. T. } \\
\text { Brito (2007) }\end{array}$ & $\begin{array}{l}\text { Psicol. cienc. } \\
\text { prof. }\end{array}$ & $\begin{array}{l}\text { Familiar Sistêmica } \\
\text { de Wagner }\end{array}$ & \begin{tabular}{|l} 
Analisar a percepção de \\
jovens adultos sobre o \\
rompimento conjugal de seus \\
pais.
\end{tabular} & $\begin{array}{l}\text { Qualitativo: entrevista com } \\
14 \text { homens e } 16 \text { mulheres } \\
\text { com idade entre } 21 \text { e } 29 \\
\text { anos, de classe média. } \\
\end{array}$ & $\begin{array}{l}\text { Percepções negativas: tornar-se o centro } \\
\text { das desavenças ocorrendo dificuldade } \\
\text { para aceitar novos relacionamentos dos } \\
\text { pais. }\end{array}$ \\
\hline $\begin{array}{l}\text { Letícia H. } \\
\text { Kunrath } \\
(2006)\end{array}$ & Psicol. rev. & $\begin{array}{l}\text { Sistêmica de } \\
\text { Bronfenbrenner e } \\
\text { Hoffmann }\end{array}$ & $\begin{array}{l}\text { Estudar os pais de crianças } \\
\text { com TDA/H, identificando } \\
\text { suas estratégias educativas. }\end{array}$ & $\begin{array}{l}\text { Qualitativo: grupo focal e } \\
\text { entrevistas individuais com } 7 \\
\text { casais. }\end{array}$ & $\begin{array}{l}\text { As estratégias utilizadas são: negociação, } \\
\text { bater, castigo, chantagem e a tomada de } \\
\text { consciência. }\end{array}$ \\
\hline $\begin{array}{l}\text { Luiza M. O. B. } \\
\text { Silveira } \\
(2005)\end{array}$ & Aletheia & $\begin{array}{l}\text { Sistêmica de } \\
\text { Hoffman }\end{array}$ & $\begin{array}{l}\text { Comparar o uso de pais e } \\
\text { mães estratégias de } \\
\text { educativas desejáveis e } \\
\text { indesejáveis com os filhos } \\
\text { adolescentes. }\end{array}$ & $\begin{array}{l}\text { Quantitativo: survey com } 20 \\
\text { pais e } 20 \text { mães com } 45 \text { anos } \\
\text { para homens e } 41 \text { para } \\
\text { mulheres com ensino } \\
\text { superior. }\end{array}$ & $\begin{array}{l}\text { A rede de apoio familiar que diminui os } \\
\text { efeitos negativos das condutas } \\
\text { indesejáveis. }\end{array}$ \\
\hline $\begin{array}{l}\text { Maria C. L. A. } \\
\text { Amazonas } \\
(2006)\end{array}$ & Ágora & $\begin{array}{l}\text { Psicodinâmica de } \\
\text { Roudinesco }\end{array}$ & $\begin{array}{l}\text { Discutir o impacto cultural e } \\
\text { subjetivo provocado pelas } \\
\text { novas formas de } \\
\text { parentalidade. }\end{array}$ & Estudo teórico. & $\begin{array}{l}\text { Independente da configuração familiar, o } \\
\text { fundamental é que as crianças sejam } \\
\text { cuidadas, desejadas e educadas. }\end{array}$ \\
\hline $\begin{array}{l}\text { Marie R. Moro } \\
(2005)\end{array}$ & $\begin{array}{l}\text { Rev. latinoam. } \\
\text { psicopatol. } \\
\text { fundam. }\end{array}$ & $\begin{array}{l}\text { Psicodinâmica de } \\
\text { Freud e Winnicott }\end{array}$ & $\begin{array}{l}\text { Compreender a parentalidade } \\
\text { pela perspectiva } \\
\text { psicodinâmica. }\end{array}$ & Estudo teórico. & $\begin{array}{l}\text { Alguns bebês são mais bem dotados do } \\
\text { que outros afetando a relação com o } \\
\text { adulto. }\end{array}$ \\
\hline $\begin{array}{l}\text { Régine P. } \\
\text { França (2008) }\end{array}$ & $\begin{array}{l}\text { Rev. bras. } \\
\text { psicanál. }\end{array}$ & $\begin{array}{l}\text { Psicodinâmica de } \\
\text { Winnicott }\end{array}$ & $\begin{array}{l}\text { Estudar a parentalidade de } \\
\text { pais no contexto de } \\
\text { dependência total do filho } \\
\text { bebê. }\end{array}$ & Estudo teórico. & $\begin{array}{l}\text { A parentalidade é explorada como } \\
\text { experiência comum dos pais, como } \\
\text { também patologia. }\end{array}$ \\
\hline
\end{tabular}

Pode-se asseverar que os estudos da categoria Parentalidade na transição de vida têm como tese consensual perceber como relevantes no exercício da parentalidade as relevâncias da história de vida no processo de transição de vida e na relação pai-filho para esse momento do desenvolvimento e, especialmente, as estratégias educacionais e a parentalidade como momento significativo no curso do desenvolvimento da pessoa.

\section{DISCUSSÃO}

A identificação do crescimento das produções nacionais nos últimos anos sobre parentalidade indica um interesse maior dos pesquisadores sobre o desenvolvimento adulto, provavelmente, causado pelos mesmos motivos dos Estados Unidos e da Europa, isto é, o envelhecimento da população, que, diferentemente dessas localidades, no Brasil, ocorreu mais expressivamente no final do século XX (Neri, 2006). Assim, o decréscimo de produções em 2010 não demonstra, necessariamente, o desinteresse pela temática, mas a provável não indexação de volumes.

Essa informação concorda com as de outros estudos internacionais e nacionais sobre parentalidade, as quais consideram que a retomada dos estudos sobre fenômenos do desenvolvimento adulto recentes na Psicologia 
se deve às mudanças sociais, que têm interferido nas formas de manifestação da parentalidade (Bronfenbenner, 2001; Neri, 2006; Slater, 2003).

A existência também de uma quantidade expressiva de estudos teóricos revela uma preocupação dos pesquisadores com a promoção de backgounds conceituais concernentes ao contexto nacional. Isso é notório nos primeiros estudos sobre parentalitade, feitos em 2001, pela teorização da parentalidade justificada pelas mudanças socioeconômicas, tecnológicas e de relações de parentesco e filiação (Benghozi, 2001; Lowenkron, 2001). Assim, a polissemia teórica é apresentada com o fim de se compreender esse fenômeno dentro do contexto brasileiro, adequando os referenciais consagrados, especialmente na Psicologia do Desenvolvimento e na Psicologia Clínica.

As maiores porcentagens identificadas de adultos de meia-idade e adultos jovens nas amostras dos estudos pesquisados, assim como a inclusão de idosos, adolescentes e crianças, apontam para uma ampliação da compreensão da parentalidade pelas diversas fases do desenvolvimento, ratificando, assim, a perspectiva de Erikson (1950/1976), para quem esse fenômeno está ligado a mais de uma fase do desenvolvimento humano.

Somado a isso, a preponderância de mulheres como as principais participantes das investigações e como as primeiras autoras ressalta a proposta de Erikson (1950/1976), que percebe a parentalidade como um processo de desenvolvimento necessário e de interesse especialmente das mulheres, por elas precisarem desenvolver seu "espaço interno produtivo" (Erikson, 1968/1972, p. 125).

Nessa direção, Bastos e colegas, em seus estudos sobre relações familiares e gênero (Carvalho, Bastos, Rabinovich \& Sampaio, 2006; Carvalho, Cavalcanti, Almeida \& Bastos, 2008), ratificam a relevância, particularmente por parte da mulher, de exercer uma posição geralmente de principal cuidadora ou de terceira responsável, ou seja, de auxiliar e incentivar o desenvolvimento da outra pessoa (Bronfenbrenner, 2011).

Assim, aspectos de gênero nos estudos sobre parentalidade, como outros fenômenos psicológicos, são preeminentes por serem fenômenos do homem e da mulher que envolvem as experiências que costumam ter nos seus ciclos de vida, sendo (sempre) relevante considerar quanto o gênero pode ser um fator que intervém na escolha das investigações e nos seus resultados.

As categorias oriundas das leituras sugerem maior interesse de pesquisa sobre a parentalidade dentro do desenvolvimento não normativo, relacionado à vivência da parentalidade na adolescência e às dificuldades apresentadas no seu exercício nas relações entre pais e filhos.

Esse dado converge com investigação apresentada por Bronfenbrenner (2011), a qual mostra a relevância de estudos e práticas de intervenção na parentalidade devido ao aumento na desordem do desenvolvimento de crianças, jovens e familiares. Essa preocupação com as gerações futuras ocorre, para 0 autor, pelo aumento do individualismo na sociedade e pelas fragilidades das instituições de proteção infantojuvenil e de apoio à educação e saúde da família.

\section{CONSIDERAÇÕES FINAIS}

Identificar como o fenômeno da parentalidade está sendo discutido nos periódicos brasileiro é perceber como a Psicologia está trabalhando com 0 desenvolvimento adulto e social, buscando promover alternativas e compreensões de um fenômeno do desenvolvimento relevante para diversas áreas psicológicas. Nesta investigação conseguiu-se mapear como os pesquisadores estudam esse fenômeno, os métodos empregados, seus interesses e como relacionam esse fenômeno com o ciclo de vida.

Destaca-se, nos resultados deste levantamento, o maior interesse dos pesquisadores pelo desenvolvimento não normativo dentro do contexto da parentalidade. Nessa direção, recomenda-se a promoção de estudos que possam compreender aspectos normativos do desenvolvimento como a entrada na escola, a puberdade e o casamento. Um estudo de Rothrauff e Cooney (2008) desenvolvido com o objetivo de avaliar a associação entre bem-estar psicológico e generatividade é um exemplo disso. Um delineamento quantitativo composto por uma amostra de 289 adultos sem filhos e 2.218 pais e mães teve entre os seus resultados a ausência de diferença significativa no bem-estar 
psicológico entre homens e mulheres com e sem filhos, a necessidade de estudos sobre desenvolvimento positivo que objetivem preencher essa lacuna, assim como investigações sobre a parentalidade exercida por homens, idosos e outros cuidadores.

Como assevera Bronfenbrenner (2011), é necessário que os cientistas se engajem em intervenções visando atender às necessidades das crianças e da sociedade como um todo, e não apenas dos adultos. As crianças e os bebês precisam de cuidado de seus pais e de outros adultos, e estes, por sua vez, necessitam de apoio das entidades empregadoras, das escolas, da sociedade e do poder público. Ainda para o autor, sem o exercício da parentalidade somos incapazes de promover mudanças no mundo no qual existimos, mostrando que o exercício da parentalidade em preferência a posicionamentos individualistas possibilita a realização de um desenvolvimento positivo.

\section{REFERÊNCIAS}

Ariès, P. (1981). História Social da criança e da família. (D. Flaksman, Trad.) Rio de Janeiro: Editora Guanabara.

Benghozi, P. (2001). Parentalidade, autoridade, laço e lei. Psicologia Clínica, 13(2), 39-51.

Bentley, E. (2007). Adulthood. London, New York: Routledge.

Bronfenbrenner, U. (2011). Bioecologia do desenvolvimento humano: Tornando os seres humanos mais humanos (A. Carvalho-Barreto, Trad.). Porto Alegre: Artmed.

Bühler, C. (1935). The curve of life as studied in biographies. The Journal of Applied Psychology, 19(4), 405-409.

Carvalho, A. M. A., Bastos, A. C. S. B., Rabinovich, E. P., \& Sampaio, S. M. R. (2006). Vínculos e redes sociais em contextos familiares e institucionais: Uma reflexão conceitual. Psicologia em Estudo, 11(3), 589-598.

Carvalho, A. M. A., Cavalcanti, V. R. S., Almeida, M. A., \& Bastos, A. C. S. (2008). Mulheres e cuidado: Bases psicobiológicas ou arbitrariedade cultural? Paideia, 18(41), 431-444.
Erikson, E. H. (1972). Identidade: Juventude e crise. Rio de Janeiro: Zahar. (Originalmente publicado em 1968).

Erikson, E. H. (1976). Infância e sociedade (2 $2^{\mathrm{a}}$ ed.) Rio de Janeiro: Zahar (Originalmente publicado em 1950).

Fávero, M. H. (2007). Paradigme personnel et champ conceptuel: implications pour les situations didactiques. In M. Merri (Org.), Activité humaine et conceptualisation. Questions à Gérard Verganaud (pp. 625-634). Toulouse: Universitaires du Mirail.

Fávero, M. H., \& Souza, C. M. S. G. (2001). Resoluções de Problemas em Física: revisão de pesquisa, análise e análise. Investigações em Ensino de Ciências, 6(2), 143-196.

Furtino, R. S., \& Martins, S. (2006). Adoção por homossexuais - uma nova configuração familiar sob os olhares psicológicos e do direito. Aletheia, 24, 115-121.

Hart, D., Southerland, N., \& Atkins, R. (2003). Community service and adult development. In J. Demick \& C. Andreoletti (Orgs.), Handbook of adult development (pp. 585-597). New York: Springer.

Lowenkron, A. M. (2001). Maternidades: Novas configurações? Revista Brasileira de Psicanálise, 34(3), 823-842.

Neri, A. (2006). O legado de Paul B. Baltes à Psicologia do Desenvolvimento e do envelhecimento. Temas em Psicologia, 14(1), 17-34.

Rothrauff, T., \& Cooney, T. M. (2008). The role of generativity in psychological well-being: Does it differ for childless adults and parents? Journal of Adult Development, 15, 148-159.

Satude, J.-R. (1995). O desenvolvimento adulto de C. G. Jung. São Paulo: Cultrix.

Slater, C. L. (2003). Generativity versus stagnation: An elaboration of Erikson's adult stage of human development. Journal of Adult Development, 10(1), 53-65.

\footnotetext{
Endereço para correspondência: André de Carvalho-Barreto. Universidade de Brasília, Instituto de Psicologia, Departamento de Psicologia Escolar e do Desenvolviemento, CEP: 70910-900, Brasília-DF, Brasil. E-mail: andrecarvalhobarreto@yahoo.com.br.
} 